\title{
Pharmacokinetics, biodistribution and antitumour effects of Sclerotium rolfsii lectin in mice
}

\author{
ANUPAMA $\mathrm{S}^{1}$, PREETI LAHA ${ }^{2}$, MAMTA SHARMA ${ }^{1}$, KAMAL PATHAK $^{2}$, SANJAY BANE $^{2}$, \\ ARVIND D. INGLE ${ }^{2}$, VIKRAM GOTA ${ }^{2}$, RAJIV D. KALRAIYA ${ }^{2}$, LU-GANG YU ${ }^{3}$, \\ JONATHAN M. RHODES ${ }^{3}$, BALE M. SWAMY ${ }^{1}$ and SHASHIKALA R. INAMDAR ${ }^{1,3}$ \\ ${ }^{1}$ Department of Studies in Biochemistry, Karnatak University, Dharwad 580003; \\ ${ }^{2}$ Advanced Centre for Treatment, Research and Education in Cancer, Kharghar, Navi Mumbai 410210, India; \\ ${ }^{3}$ Department of Gastroenterology, Institute of Translational Medicine, University of Liverpool, Liverpool L69 3BX, UK
}

Received November 18, 2016; Accepted January 16, 2017

DOI: $10.3892 /$ or.2017.5545

\begin{abstract}
Sclerotium rolfsii lectin (SRL) is a lectin isolated from the fungus Sclerotium rolfsii and has exquisite binding specificity towards the oncofetal Thomsen-Friedenreich antigen (TF-Ag; Gal $\beta 1-3 \mathrm{GalNAc} \alpha-O$-Ser/Thr) and its derivatives. Previous studies have shown that SRL inhibits the proliferation of human colon, breast and ovarian cancer cells in vitro and suppresses tumour growth in mice when introduced intratumourally. The present study assessed the effect of SRL on tumour growth when introduced intraperitoneally in $\mathrm{BALB} / \mathrm{c}$ nude mice and investigated the pharmacokinetics and biodistribution of SRL in Swiss albino mice. When 9 doses of SRL ( $30 \mathrm{mg} / \mathrm{kg}$ body weight $/$ mice) was administered to BALB/c nude mice bearing human colon cancer HT-29 xenografts, a substantial reduction in tumour size was observed. A $35.8 \%$ reduction in tumour size was noted in the treated animals after 17 days. SRL treatment also inhibited angiogenesis, and the tumours from the treated animals were observed to carry fewer blood vessels and express less angiogenesis
\end{abstract}

Correspondence to: Dr Shashikala R. Inamdar, Department of Studies in Biochemistry, Karnatak University, Dharwad 580003, India

E-mail: srinamdar2009@gmail.com

Abbreviations: CRC, colorectal cancer; SRL, Sclerotium rolfsii lectin; HT-29, human colorectal adenocarcinoma grade II cell line; TF, Thomsen-Friedenreich antigen; AAL, Agrocybe aegerita lectin; ABL, Agaricus bisporus lectin; PNA, peanut agglutinin; SNA, Sambucus nigra lectin; HPA, Helix pomatia lectin; VCA, Viscum album var. coloratum agglutinin; PCL, Polygonatum cyrtonema lectin; Con A, Concanavalin A lectin; BSA, bovine serum albumin; DMEM, Dulbecco's modified Eagle's medium; FCS, fetal calf serum; GalNAc, $N$-acetyl-D-galactosamine; GlcNAc, $N$-acetyl-Dglucosamine; HRP, horseradish peroxidase; $\mathrm{PBS}$, phosphate-buffered saline; SDS, sodium dodecyl sulphate; TBS, Tris-buffered saline; RT, room temperature; PBST, phosphate-buffered saline Tween-20

Key words: pharmacokinetics, biodistribution, Sclerotium rolfsii lectin, tumour regression, anti-angiogenesis marker protein CD31, than that from the control animals. Pharmacokinetics and biodistribution analysis revealed that SRL was detected in the serum after $1 \mathrm{~h}$ and its level peaked after $24 \mathrm{~h}$. SRL was not detected in any of the organs apart from the kidney where a trace amount was detected after $24 \mathrm{~h}$ of SRL injection. No significant changes were observed in any of the biochemical parameters tested including SGOT, SGPT, LDH, CREAT and BUN in the SRL-treated mice compared to these levels in the controls. This suggests that SRL has good potential to be developed as a therapeutic agent for cancer treatment and warrant further investigations in vivo and subsequent clinical trials.

\section{Introduction}

Cancer is one of the major life threatening diseases worldwide (1). Colorectal cancer is the third leading cause of cancer-associated mortality in both men and women in the world (2). Regular screening increases the likelihood that colorectal cancer is detected at an early stage, more likely to be cured and with faster recovery (3). Although significant progress has been made over the past few decades, effective treatment of this disease is still lacking. It is believed that targeted therapy that focuses on specific molecules or signalling pathways hold the key for more effective treatment of this disease than the currently used chemotherapy.

Lectins, a group of highly diverse proteins of non-immune origin that are ubiquitous in nature, recognize specific carbohydrate structures. Tumour cells in general display different carbohydrate profiles on the cell surface compared to nontransformed cells which can be detected using lectins. Lectins can reasonably differentiate malignant tumours from normal cells, and hence are used for cancer diagnosis and some are also being studied for their possible use as therapeutic agents (4). Lectins from edible mushrooms, such as Agaricus bisporus, Agrocybe aegerita I \& II, Kurkowa lectin Pleurotuseous, Tricholomamongolicum and Pholiotaadiposa, have been shown to exert antiproliferative effects in cancer in vitro and antitumor effects in vivo (5-11). The two main properties of lectins that is, selectivity and cytotoxicity, have been exploited for devising therapeutic strategies against cancer. 
Sclerotium rolfsii, lectin (SRL) purified from the fungus Sclerotium rolfsii (12) has been shown to have exquisite binding specificity toward Thomsen-Friedenreich antigen (TF-Ag; Gal $\beta 1-3$ GalNAc $\alpha-O$-Ser/Thr) and its derivatives (13). The TF antigen is highly expressed by $>90 \%$ of tumours and rarely occurs in normal tissues (14). The crystal structure of SRL determined at 1.1 Å resolution, revealed two carbohydrate binding sites (15). Our previous studies have shown that SRL binds specifically to human cancerous colon but not to normal colon and exhibits strong antiproliferative activity in human colon cancer (HT29 and DLD1) (16), breast cancer (MCF-7 and ZR-75) and ovarian cancer (PA-1) cells by inducing cellular apoptosis $(17,18)$. Recently, we demonstrated that the presence of SRL affects multiple cell signalling pathways with early effects on MAPK- and c-JUN-associated cell proliferation pathways followed by miRNA-associated cell activity and apoptosis pathways. Lectin affinity purification has extracted a total of 25 proteins in HT29 cells, including keratins, heat shock proteins HSP-60 and HSP-90, ATP synthase subunit $\alpha$, mitochondrial retinal dehydrogenase 1 , actin cytoplasmin 2 , tubulins, pyruvate kinase-M, Annexin A2, peroxiredoxin-1, prohibitin, $\alpha$-enolase and ADP/ATP translocase 2 that are known to be involved in cell survival, apoptosis and tumorigenesis $(19,20)$. These effects of SRL together with its exquisite binding specificity towards TF-Ag-associated glycans prompted us to investigate the possibility of developing SRL as a therapeutic agent.

\section{Materials and methods}

Materials. Protease Inhibitor Cocktail Set III was obtained from Calbiochem (Darmstadt, Germany); CD-31 (PECAM-1) was obtained from Invitrogen (Carlsbad, CA, USA) and Dulbecco's modified Eagle's medium (DMEM) and fetal calf serum (FCS) were obtained from Gibco-Invitrogen (Paisley, UK). Bovine serum albumin (BSA), streptavidin-horseradish peroxidase, 3,3',5,5'-tetramethylbenzidine (TMB) and poly-Llysine solution were obtained from Sigma-Aldrich (St. Louis, MO,USA).Taq DNA polymerase was obtained from Invitrogen. Oligonucleotide primers and Tris buffer were obtained from Sigma-Aldrich and dNTPs from Fermentas (Waltham, MA, USA). 3-3'-Diaminobenzidine chromogen $/ \mathrm{H}_{2} \mathrm{O}_{2}$ substrate in buffer solution ( $\mathrm{pH}$ 7.5) (DAB kit) and rabbit anti-SRL polyclonal antisera were obtained from Bangalore Genei India Pvt. Ltd. (Bangalore India). Caspase-3 (3G2) mouse mAb was procured from Cell Signaling Technology, Inc. (Danvers, MA, USA). Species-specific HRP-labelled secondary antibodies were procured from Bio-Rad Laboratories (Hercules, CA, USA). Anticoagulated tubes were obtained from Greiener Bio-One (1 ml K3E K3EDTA; Frickenhausen, Germany) and a flat bottom 96-well micro-test plate were obtained from Tarsons (Kolkata, India). All other reagents were of analytical grade and Milli-Q water was used for all the preparations.

Purification of Sclerotium rolfsii lectin (SRL). Purification of SRL from the sclerotial bodies was carried out as previously described (12). Briefly, SRL was extracted from powdered sclerotial bodies with $50 \mathrm{mM}$ acetate buffer containing $100 \mathrm{mM}$ $\mathrm{NaCl}(\mathrm{pH} 4.3)$ and subjected to $30 \%$ methanol precipitation followed by ion exchange chromatography on CM cellulose matrix and finally purified on a Superdex G-75 gel filtration column. The purified lectin was used for biodistribution and efficacy studies. The lectin activity was routinely determined by the 2 -fold serial dilution method using trypsinised human erythrocytes.

Purification of polyclonal SRL antibodies from Protein A agarose column. Custom designed anti-SRL polyclonal antibodies were purified from immunized rabbit serum (from Bangalore Genei India) by subjecting to $50 \%$ ammonium sulphate precipitation, followed by affinity chromatography on a Protein A agarose column equilibrated with $100 \mathrm{mM}$ phosphate buffer ( $\mathrm{pH}$ 7.2) containing $150 \mathrm{mM} \mathrm{NaCl}$ phosphate-buffered saline (PBS). Bound SRL antibodies were eluted with $100 \mathrm{mM}$ glycine- $\mathrm{HCl}$ ( $\mathrm{pH} 2.5$ ), dialysed against PBS and stored at $-20^{\circ} \mathrm{C}$.

Cell culture. Human colon cancer HT29 cells were obtained from the European Cell Culture Collection via the Public Health Laboratory Service (Porton Down, UK). HT29 cells were cultured in DMEM supplemented with $10 \%$ FBS, $100 \mathrm{units} / \mathrm{ml}$ penicillin and $100 \mu \mathrm{g} / \mathrm{ml}$ streptomycin (complete DMEM) at $37^{\circ} \mathrm{C}$ in $5 \% \mathrm{CO}_{2}$.

Mice. All animal experiments were carried out at the Advanced Centre for Treatment, Research and Education in Cancer with approval from the Ethics Committee (IRB approval no. 07/2012) of Tata Memorial Centre-ACTRECIAEC (Institutional Animal Ethics Committee). Inbred female BALB/c nude mice (6-8 weeks old, weighing 18-22 g) for efficacy studies and male Swiss albino mice (6-8 weeks old, weighing 20-25 g) for pharmacokinetics and biodistribution studies were used. The animals were housed in groups of 4-5 per polycarbonate cage under individually ventilated caging systems (IVC's) under controlled conditions of $55 \pm 5 \%$ humidity, $22 \pm 2^{\circ} \mathrm{C}$ temperature, and light cycle $(12: 12 \mathrm{~h})$. All mice were provided with easy access to in-house pelleted feed and with ad libitum UV-treated water and were monitored daily for general health status.

Efficacy studies of SRL on tumour growth in BALB/c nude mice. HT29 cells were suspended at $1 \times 10^{7}$ cells $/ \mathrm{ml}$ in DMEM and a cell suspension $(0.1 \mathrm{ml})$ was injected subcutaneously into two donor mice. After 4 weeks, the tumours from these donor mice were excised, chopped into 2- to 3-mm fragments and a single piece of tumour was transplanted subcutaneously into each of $12 \mathrm{BALB} / \mathrm{c}$ nude mice. Tumours were allowed to grow to reach the appropriate size of $5-6 \mathrm{~mm}$, i.e. $80-120 \mathrm{~mm}^{3}$ in volume and animals were divided randomly into 2 groups of 5 mice in each group, one for SRL treatment (T) and other used as a control (TBS, C). Mice were intraperitoneally administered SRL ( $30 \mathrm{mg} / \mathrm{kg}$ body weight $/$ mouse) in TBS (pH 7.5) on every other days for 17 days for a total of 9 doses. The mice in the control group were injected intraperitoneally with TBS at the same units (5-10 UI) and maintained for 2 weeks after the last dose. The mice were weighed and tumour volume was also determined by measuring the length $(\mathrm{L})$ and width $(\mathrm{W})$ of the tumour after each injection. The tumour volume at day $\mathrm{n}(\mathrm{TVn})$ was calculated as TV $\left(\mathrm{mm}^{3}\right)=\left(\mathrm{L} \mathrm{x} \mathrm{W}^{2}\right) / 2$. The relative tumour volume at day n (RTVn) vs. day 0 was expressed according to 
the formula: RTVn $=\mathrm{TVn} / \mathrm{TV0}(21,22)$. Regression of tumour $\mathrm{T} / \mathrm{C}(\%)$ in the treated vs. control mice was calculated using: $\mathrm{T} / \mathrm{C}(\%)=($ mean RTV of treated/control group) $\mathrm{x} 100$. The changes in the tumour size of the treated mice at different time-points compared to the control were used for monitoring the efficacy of the lectin. Mice were sacrificed 2 weeks after the last dose, and whole blood was collected in tubes coated with anticoagulant and used for analysis of total blood cell count, hemoglobin content, WBC and platelet count. Tumours were excised and organs such as liver, kidney and lung were collected directly in PBS to remove the blood traces, wrapped in aluminium foil and stored at $-80^{\circ} \mathrm{C}$ until further use for immunohistological analysis. Excised tumours were also snap frozen and stored at $-80^{\circ} \mathrm{C}$ for STR analysis.

PCR analysis of short tandem repeat (STR). In order to ascertain the human origin of the tumours using short tandem repeat (STR) method (23), a small piece of the tumour tissues was collected from BALB/c mice with HT-29 xenograft, excised after 2 weeks from the last dose of injection. These tissues were snap frozen and stored at $-80^{\circ} \mathrm{C}$ for extraction of DNA. DNA was extracted from the samples using phenol chloroform extraction followed by ethanol precipitation. The DNA precipitates were suspended in Tris-EDTA (TE) buffer, $\mathrm{pH}$ 8.4. The extracted DNA was subjected to PCR amplification using human-specific microsatellite primers (forward, 5'-TGCCATTTGTGGGTACATTC-3' and reverse, 5'-TTG TGTTTCTTTTTCTGTTCCTACA-3'). In brief, $100 \mathrm{ng}$ of target DNA was amplified in a $15-\mu 1$ reaction volume containing 5 IU of Taq DNA polymerase, 0.4 pM each oligonucleotide primer, $10 \mathrm{mM}$ Tris buffer, $3.5 \mathrm{mM} \mathrm{MgCl}_{2}, 0.4 \mathrm{mM}$ each of dNTPs. PCR was performed with a 5-min denaturation at $94^{\circ} \mathrm{C}$ followed by 34 cycles of a $20-\sec$ denaturation at $94^{\circ} \mathrm{C}$, a $20-\sec$ annealing at $58^{\circ} \mathrm{C}$, and a $30-\mathrm{sec}$ elongation at $72^{\circ} \mathrm{C}$ in a thermal cycler (Eppendorf, Hauppauge, NY, USA). Amplicon was separated on $2 \%$ agarose gel and visualized by UV light.

Pharmacokinetics and biodistribution studies. Swiss albino mice were randomized into two groups, the control group (TBS) and the SRL-treated group which included 4 timepoints $(1,6,24$ and $48 \mathrm{~h})$ with 3 animals for each time-point. Lectin was prepared in TBS ( $\mathrm{pH} 7.5$ ), hence TBS served as the vehicle control. Animals were injected intraperitoneally with TBS and SRL ( $24 \mathrm{mg} / \mathrm{kg}$ body weight/mouse) and maintained for different time-points and blood was collected from the treated and control mice by retro-orbital bleeding. After incubation of the blood at room temperature (RT) for $15 \mathrm{~min}$, serum was collected by centrifuging the sample at $2,500 \mathrm{rpm}$ for $15 \mathrm{~min}$ at $4^{\circ} \mathrm{C}$ and stored at $-80^{\circ} \mathrm{C}$ until further use. The pharmacokinetic profile of the serum samples was evaluated by ELISA. Serum samples collected at $24 \mathrm{~h}$ were also analysed for biochemical parameters of toxicity such as serum liver enzymes (aspartate transaminase and alanine transaminase), lactate dehydrogenase (LDH), blood urea nitrogen (BUN) and creatinine levels [carried out at Unique Bio Diagnostics Enterprises (Mumbai, India)]. Animals were then sacrificed by cervical dislocation, and the organs (liver, kidney, heart, stomach, lungs, spleen, intestine and brain) were collected directly in PBS to remove the blood traces, wrapped in aluminium foil and stored at $-80^{\circ} \mathrm{C}$ until further use for biodistribution studies by ELISA or histology.

Tissue homogenization. Tissue homogenate was prepared by taking a part of the tissue from each organ, thawed on ice, weighed in a 2-ml Eppendorf tube and extracted in extraction buffer, PBS pH 7.4 (four volume/g of organ weight). Protease Inhibitor Cocktail Set III was added to the extraction buffer (1/20th volume of the tissue weight) and subjected to homogenization using an electric homogenizer $(24,25)$. Prior to homogenization, the probe was dipped in ice and the tissue was homogenized at $4^{\circ} \mathrm{C}$ with 8-10 oscillate up- and down-strokes for soft tissues derived from organs such as the liver, stomach, small intestine, lung, spleen, kidney and brain; whereas, hard tissues from the heart required more strokes and agitation. After homogenization, each sample was centrifuged for $20 \mathrm{~min}$ at $16,000 \mathrm{rpm}$ at $4^{\circ} \mathrm{C}$ and the supernatant was collected and stored at $-80^{\circ} \mathrm{C}$ until further use for analysis.

Bioanalytical validation. A calibration curve was constructed using different concentrations of SRL (0.002-0.312 $\mu \mathrm{g} / \mathrm{ml}$ and $0.002-0.078 \mu \mathrm{g} / \mathrm{ml}$ ) including a lower limit of quantification (LLOQ) for evaluating SRL in organ and serum extracts, respectively. Analytical recovery by ELISA was evaluated by adding serum and organ extracts at a 1:100 dilution and using the respective calibration curves and measuring its recovery using the same procedure and conditions as described in the ELISA experiments. The absorbance was measured at $450 \mathrm{~nm}$ and values were plotted against the concentrations. The LLOQ was set as the lowest measurable concentration with acceptable accuracy and precision not $>20 \%$ of the expected values $(26,27)$. Precision and accuracy were determined by analyzing quality control samples (QCs). Recovery was computed by comparing responses in triplicate of extracted QCs $(28,29)$.

ELISA. Indirect ELISA was performed using 96-well plates. The plates were pre-coated with a known concentration of SRL (0.002-0.3 $\mu \mathrm{g} / 100 \mu \mathrm{l} /$ well), serum samples or tissue homogenate (1:100 dilution) in coating buffer $(15 \mathrm{mM}$ sodium carbonate and $17 \mathrm{mM}$ bicarbonate buffer, $\mathrm{pH}$ 9.6, containing $3 \mathrm{mM}$ sodium azide) and incubated overnight at $4^{\circ} \mathrm{C}$. Wells were washed thrice with $50 \mathrm{mM}$ PBS, at pH 7.4 containing $0.1 \%(\mathrm{v} / \mathrm{v})$ Tween-20 (PBST) to remove the unbound proteins. Non-specific binding was blocked by incubating with $100 \mu \mathrm{l}$ of $1 \% \mathrm{BSA}$ in PBS for $2 \mathrm{~h}$ at RT at $37^{\circ} \mathrm{C}$, followed by washing twice with PBST to remove excess blocking agent. Wells were incubated with rabbit anti-SRL polyclonal antibodies (100 $\mu \mathrm{l} /$ well, 1:10,000 dilutions in PBS) overnight at $4^{\circ} \mathrm{C}$. After washing, HRP-conjugated anti-rabbit IgG secondary antibodies (Sigma-Aldrich) at 1:10,000 dilutions were added and incubated for $2 \mathrm{~h}$ at RT at $37^{\circ} \mathrm{C}$. The colour was developed by the addition of 3,3',5,5'-tetramethylbenzidine (TMB; Sigma-Aldrich). The reaction was stopped using $4 \mathrm{M} \mathrm{H}_{2} \mathrm{SO}_{4}$ (100 $\mu \mathrm{l} /$ well) and the absorbance was recorded at $450 \mathrm{~nm}$ on a microtiter plate reader (Tecan, Crailsheim, Germany).

Histological analysis. Histochemical examinations were performed using the tissue samples of the tumors and organs including liver, spleen, kidney, heart, lung, stomach, small 
A

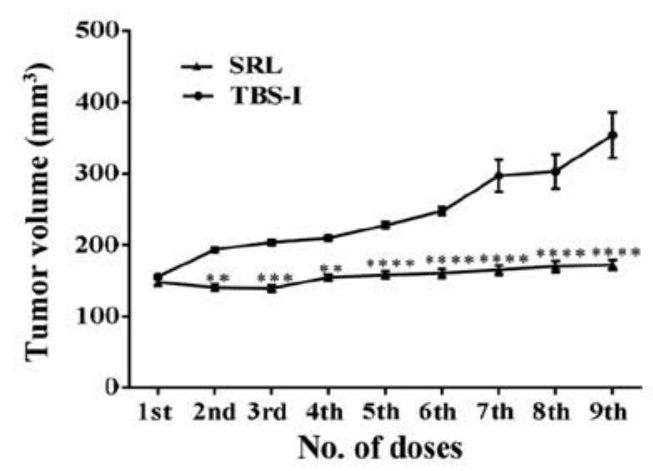

C

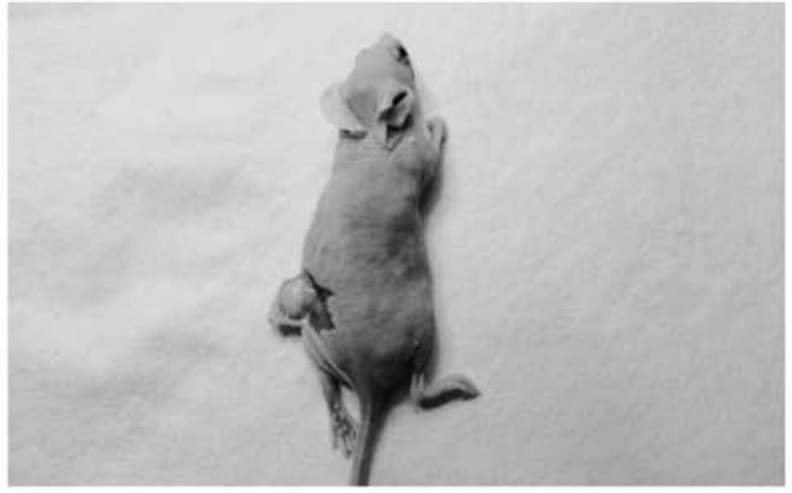

B

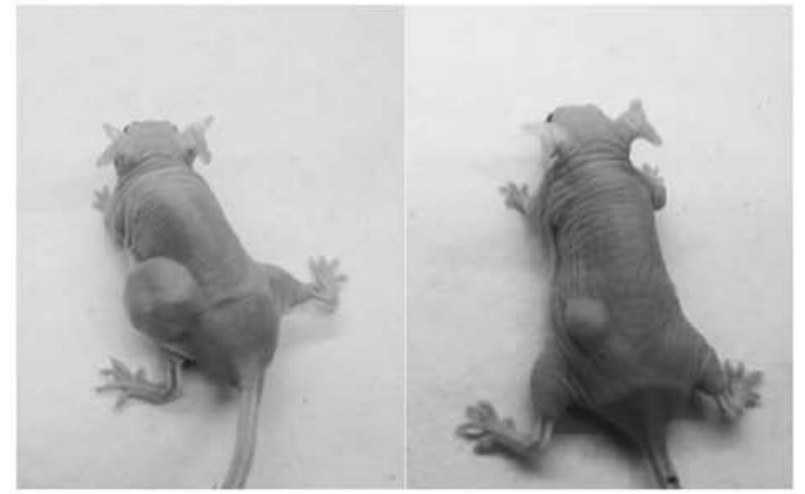

D

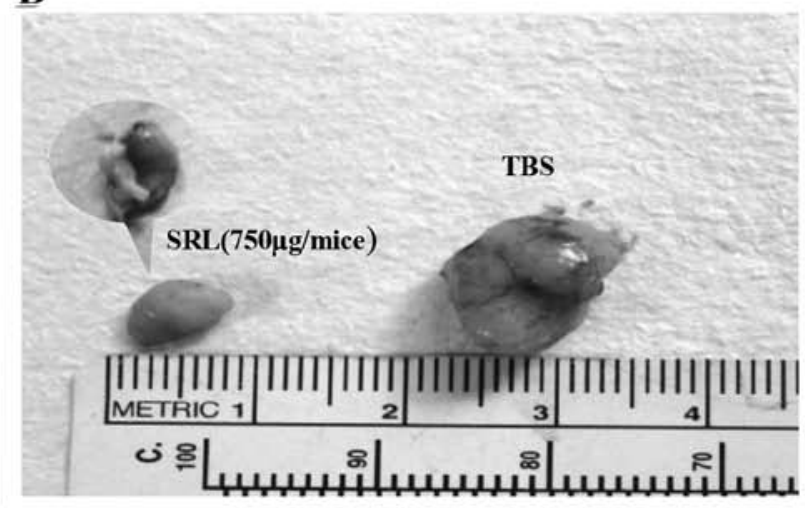

Figure 1. SRL inhibits tumour growth in mice bearing HT-29 xenografts. BALB/c nude mice bearing HT29 xenografts were injected intraperitoneally with TBS or SRL ( $30 \mathrm{mg} / \mathrm{kg}$ body weight), for a total of 9 doses and were monitored for 2 weeks after the last dose. (A) Graphical presentation of tumour volume $\left(\mathrm{mm}^{3}\right)$ of control TBS-treated and SRL-treated mice following different doses showing significant tumour growth inhibition $\left({ }^{*} \mathrm{P}<0.05,{ }^{* * *} \mathrm{P}<0.01\right.$ and $\left.{ }^{* * * *} \mathrm{P}<0.001\right)$. (B) Control-treated mouse with a tumour and SRL-treated mouse with clear tumour regression. (C) SRL-treated regressed tumour partially excised. (D) Excised tumour of an SRL-treated mouse with necrotic appearance and a tumour from a TBS-treated (control) mouse.

intestine and brain. Excised tumours were collected and fixed in $10 \%$ formalin and embedded in paraffin blocks, and $5-\mu \mathrm{m}$ sections were used for hematoxylin and eosin (H\&E) staining and for immunohistochemistry (IHC). The histological sections were observed under an optical microscope and photographed.

Immunohistochemical staining. Sections (5- $\mu$ m thick) of the SRL-treated tumours with the controls were prepared by using the tumour tissues collected from the snap-frozen samples stored at $-80^{\circ} \mathrm{C}$ and stained with a specific mouse anti-CD31 (PECAM-1) antibody (clone MEM-05) according to the manufacturer's instructions. The primary antibody (1:500) was diluted in PBS and incubated with samples at RT for $1 \mathrm{~h}$ followed by washing with TBST and then with HRP-conjugated goat anti-mouse IgG $(\mathrm{H}+\mathrm{L})$ secondary antibodies $(1: 3,000)$ diluted in PBS and incubated at RT for $1 \mathrm{~h}$. Finally the slides were developed using 3,3'-diaminobenzidine (DAB) substrate and counterstained with hematoxylin. Images (magnification, $\mathrm{x} 10$ ) were captured to monitor CD31 expression.

Statistical analysis. The antitumor activity (as measured by differences in tumor mass) was expressed as mean \pm standard deviation (SD). In vivo data and ELISA calibration curve with unknowns was analyzed using GraphPad Prism 6. The statistical significance of differences in tumor volume was determined by one-way analysis of variance (ANOVA), followed by Sidak test for three or more groups; a value of $\mathrm{P}<0.05$ was considered as significant.

\section{Results}

SRL inhibits tumour growth in BALB/c nude mice bearing HT-29 xenografts. Mice injected intraperitoneally with SRL (30 mg/kg body weight/mouse) showed significant inhibition $(35.8 \%, \mathrm{P}<0.0001)$ of tumour growth when compared with that observed in the control group (Fig. 1). The average initial tumour volume in the TBS and SRL-treated groups was $155 \pm 4.7$ and $147 \pm 10.9 \mathrm{~mm}^{3}$, respectively before tumour cell treatment and the average tumour volume after completion of 9 doses was $353 \pm 71.2$ and $171 \pm 16 \mathrm{~mm}^{3}$, respectively $(\mathrm{P}<0.001)$. No noticeable change in the weight and tumour volume of either control or treated group was observed after maintaining treatment for 14 days. The histology of the tumour sections of the SRL-treated and untreated animals showed marked differences. The SRL-treated mouse tumours appeared more like normal ones while the TBS-treated control mouse tumours showed a characteristic tumour appearance. The histology of liver sections showed that SRL-treated mice appeared normal compared to the control-treated mice bearing tumours, indicating the tumour-regressing effect of SRL (Fig. 2). Moreover, all the treated animals were healthy without any significant 
A
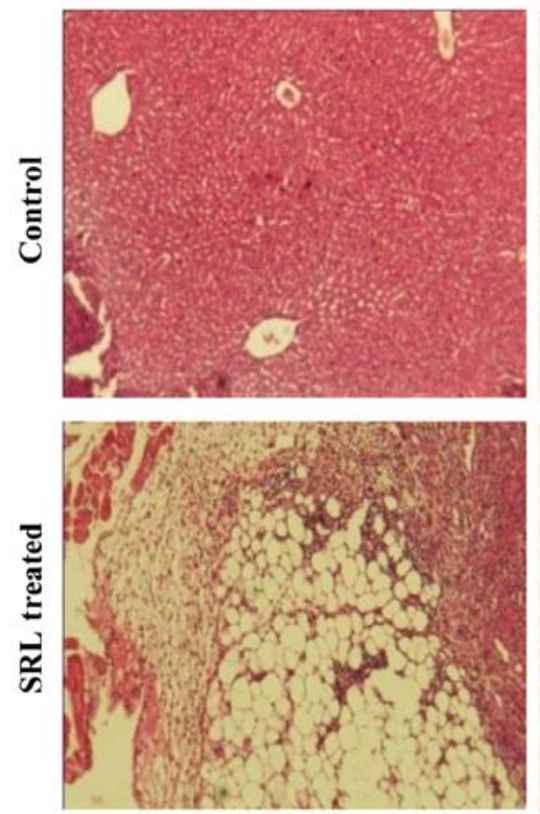

Tumor
B

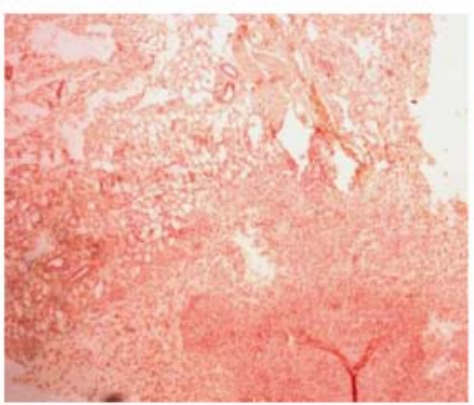

C
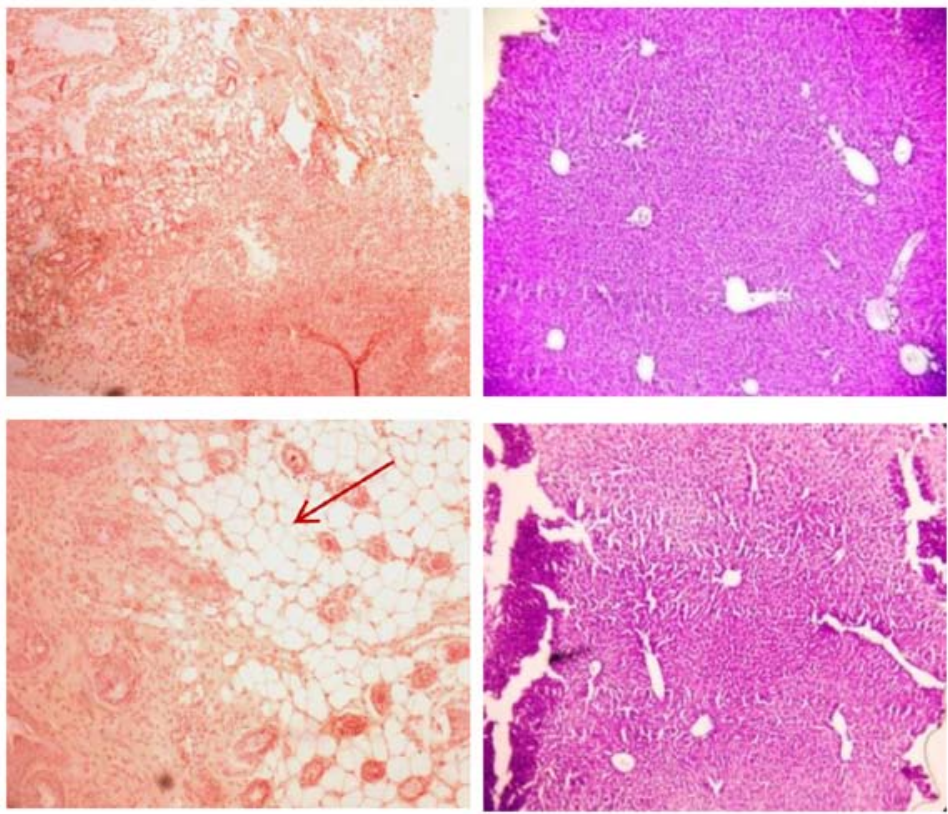

Tumor

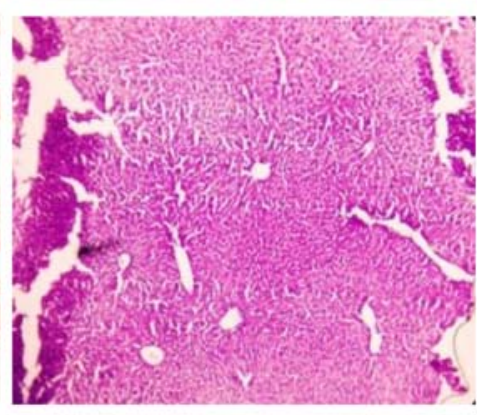

Liver

Figure 2. Immunohistochemistry analysis. Tumour sections of SRL-treated and control-treated mice were sectioned and stained with (A) H\&E and (B) antiCD31 antibody. (C) H\&E-stained liver sections of SRL-treated and control-treated mice. Arrow indicates necrotic tumour.

Table I. Toxicity studies of SRL in BALB/c nude mice.

\begin{tabular}{lcc}
\hline Parameters & SRL $(750 \mu \mathrm{g} /$ mice $)$ & Control (TBS) \\
\hline Initial body weight $(\mathrm{g})$ & 20.31 & 20.62 \\
Final body weight $(\mathrm{g})$ & 19.97 & 20.94 \\
Mortality & None & None \\
RBC $\left(10^{6} / \mu \mathrm{l}\right)$ & 9.69 & 10.33 \\
WBC $\left(10^{3} / \mu \mathrm{l}\right)$ & 1.81 & 1.38 \\
Platelet count $\left(10^{3} / \mu \mathrm{l}\right)$ & 1009 & 990 \\
Hemoglobin $(\mathrm{g} / \mathrm{dl})$ & 14.4 & 15.73 \\
\hline
\end{tabular}

RBC, red blood corpuscles; WBC, white blood corpuscles.

Table II. Toxicity studies of SRL in Swiss albino mice.

\begin{tabular}{lccr}
\hline Parameters & Std. values & TBS & SRL \\
\hline OT IU/l & $54-298$ & 98.6 & 64.5 \\
PT IU/l & $17-77$ & 43 & 25.5 \\
CREAT mg/dl & $0.3-1$ & 0.43 & 0.4 \\
BUN mg/dl & $8-33$ & 40.7 & 33.6 \\
LDH g/dl & $159-1045$ & 1132.3 & 557.5 \\
\hline
\end{tabular}

OT, aspartate aminotransferase; PT, alanine aminotransferase; CREAT, creatinine; BUN, blood urea nitrogen; $\mathrm{LDH}$, lactate dehyrogenase.

changes in body weight compared to the controls. Complete blood count $(\mathrm{CBC})$ revealed no detectable changes in the

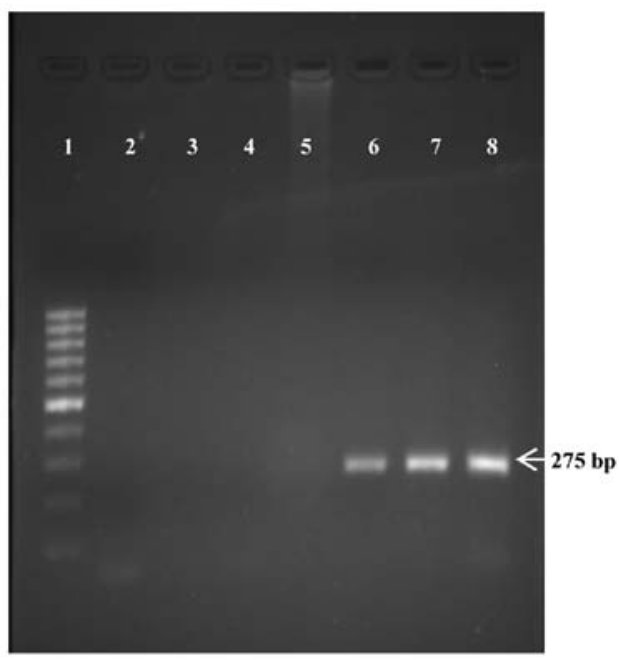

Figure 3. PCR analyses of the tumours in the experimental xenograft animals. Small pieces of the viable tumour collected from BALB/c mice with HT-29 xenografts after 9 doses of treatment, from the SRL-treated and controltreated animals were analysed by PCR. Lane 1, marker; lane 2, blank; lanes 3-5, mouse tail DNA as a negative control; and lanes 6-8, DNA from excised HT29 xenografts.

SRL-treated and TBS-treated groups (Table I). PCR analysis of the tumours obtained from the experimental mice showed similar product size of $275 \mathrm{bp}$ as that of the implanted HT29 cells, indicating that the tumours which developed in nude mice were from the implanted human cancer cells and not from the mice (Fig. 3).

Anti-angiogenic effect of SRL. SRL-treated animals also showed clear reduction in the number of blood vessels in the excised tumours compared with that from the control-treated 

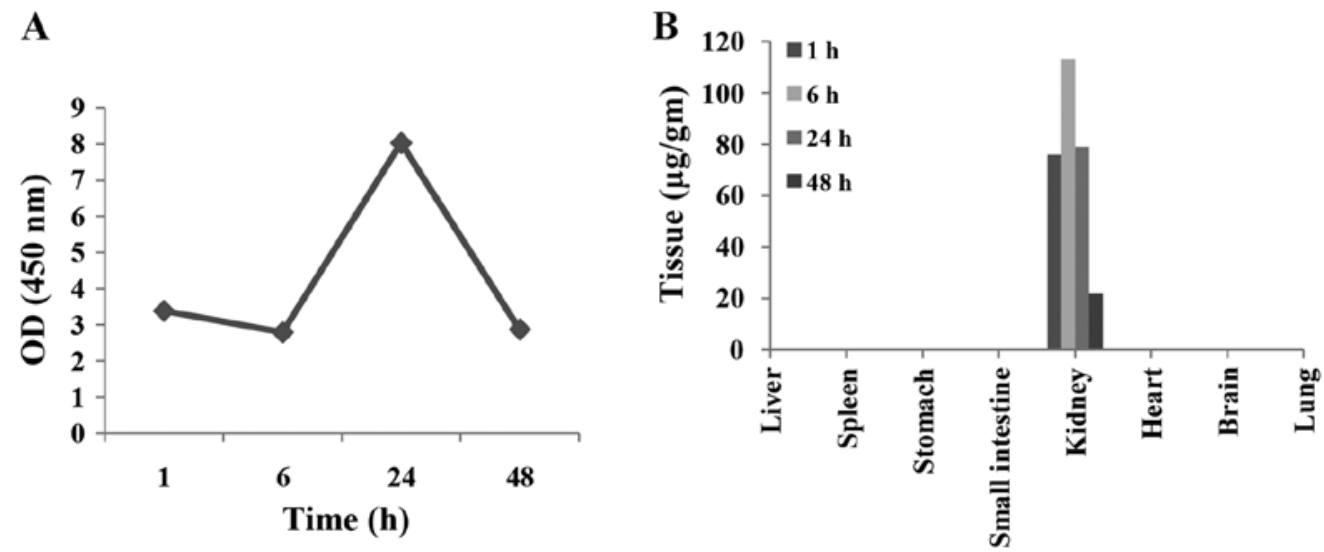

Tissues

Figure 4. Pharmacokinetics and biodistribution of SRL in mice. Swiss Albino mice were injected intraperitoneally with SRL (24 mg/kg body weight/mouse, $\mathrm{n}=3$ ), and serum and tissue samples were collected at different time-points and analysed by ELISA. (A) Concentration of SRL ( $\mu \mathrm{g} / \mathrm{ml})$ in serum at different time-points. (B) Biodistribution of SRL ( $\mu \mathrm{g} / \mathrm{gm})$ in organs at different time-points.

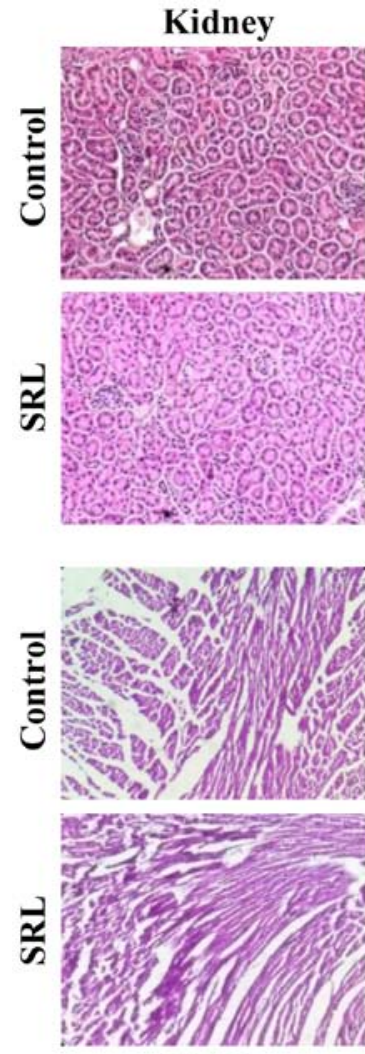

Heart
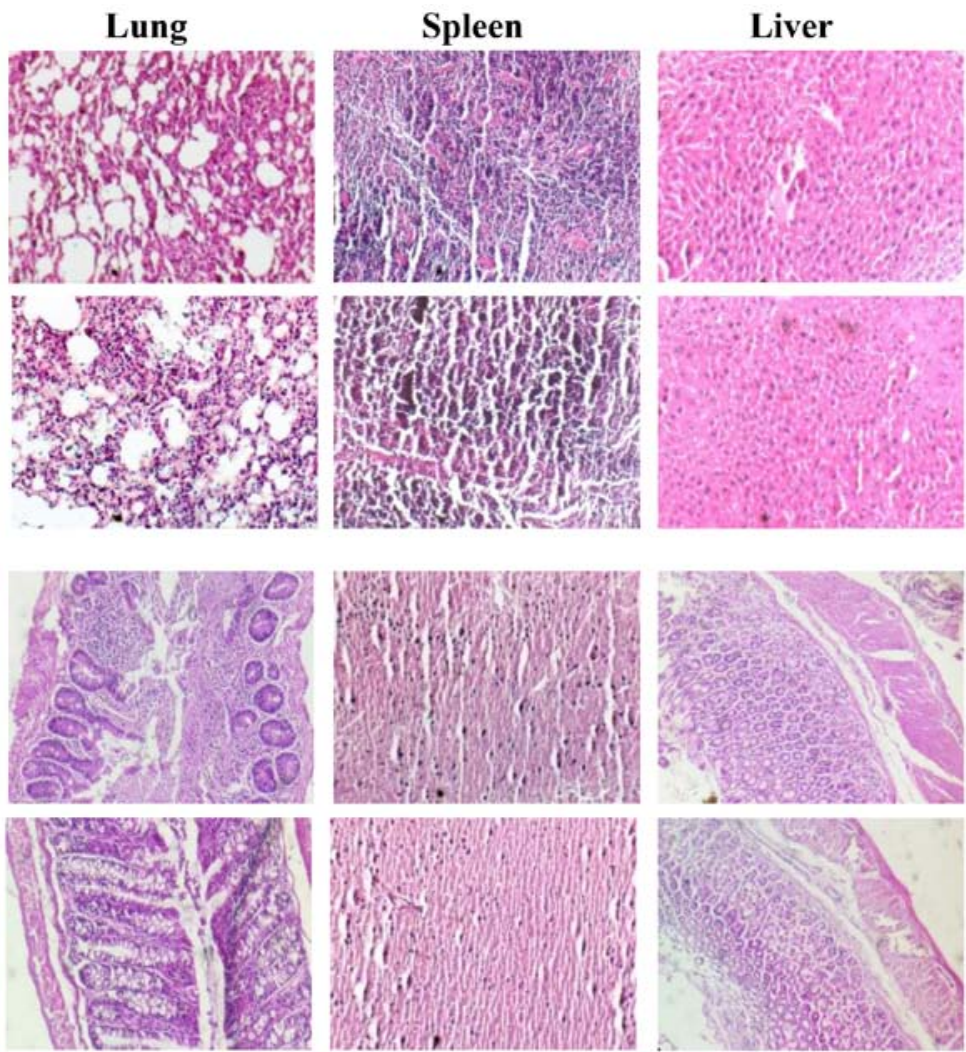

Small intestine

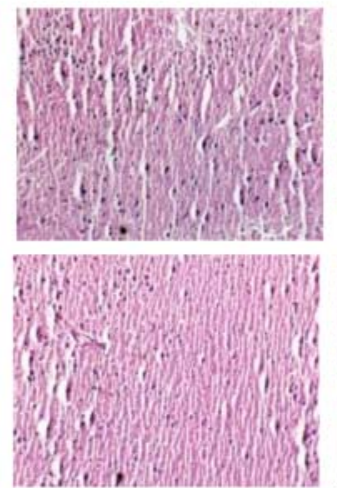

Brain

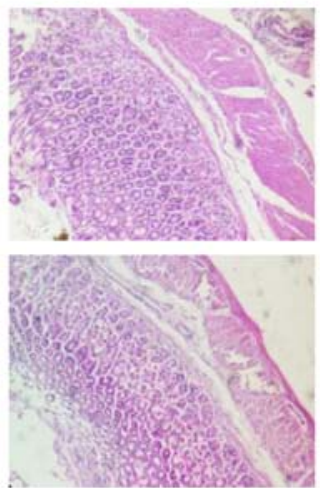

Stomach

Figure 5. Biodistribution of SRL in tissues. After SRL inoculation ( $24 \mathrm{mg} / \mathrm{kg}$ body weight/mouse) for 1, 6, 24 and $48 \mathrm{~h}$, the mouse liver, spleen, kidney, lung, brain, stomach, small intestine and heart were removed and processed for sectioning and H\&E staining. Representative images at $24 \mathrm{~h}$ are shown.

animals (Fig. 1), indicating an effect of SRL treatment on suppression of angiogenesis. The anti-angiogenesis effect of SRL was also supported by the immunohistological analysis in which the expression of PECAM (CD31), an angiogenesis marker, was observed to be much lower in the SRL-treated animals than that in the control-treated animals (Fig. 2B).

Pharmacokinetic profile. Pharmacokinetic profile of SRL in Swiss albino mice was obtained by evaluation of serum samples from the SRL-treated mice by ELISA. Mice injected with SRL ( $24 \mathrm{mg} / \mathrm{kg}$ body weight/mouse) intraperitoneally showed maximal SRL concentrations in serum at $24 \mathrm{~h}$ $(8.02 \mu \mathrm{g} / \mathrm{ml})$ (Fig. 4A). These results indicate that SRL was not accumulated in the body and was eliminated. Biochemical parameters in serum samples collected at $24 \mathrm{~h}$ and analysed for hepatic function namely SGPT, SGOT, bilirubin and cholesterol exhibited no significant alterations between the SRL-treated mice and control-treated mice. Biochemical 
parameters related to kidney functions including urea, uric acid creatinine and total protein also showed no significant differences between the SRL-treated and control group (Table II). These results indicate the non-toxic nature of SRL treatment in the mice.

In vivo biodistribution. The presence of SRL in various organs including the liver, kidney, lung, spleen, stomach, small intestine, heart and brain, respectively was analysed. The lectin was detected in trace amounts in the kidney but not in any other organ (Fig. 4B). SRL at 76, 113, 79 and $22 \mu \mathrm{g} / \mathrm{g}$ was detected in the kidney at 1, 6, 24 and $48 \mathrm{~h}$, respectively. H\&E staining of tissue sections of the different organs showed no morphological changes at $24 \mathrm{~h}$ between the SRL-treated or control-treated animals (Fig. 5). These results suggest that $\mathrm{SRL}$ is effectively cleared in the body and is non-toxic to mice.

\section{Discussion}

The present study reports that when administered intraperitoneally, SRL reduces tumour growth and inhibits angiogenesis in human colon cancer HT-29 cell xenografts in mice and is non-toxic. SRL was demonstrated to have good renal clearance and was eliminated without causing any sign of toxicity or significant changes in biochemical parameters of the mice.

Previous studies have shown that SRL induces cell apoptosis and inhibits cell growth in human colon cancer cells in vitro and suppresses tumour growth in NOD-SCID mice bearing HT-29 xenografts in vivo when injected intratumourally (16). SRL was shown to affect multiple signalling pathways in HT-29 cells by interacting with cell membrane proteins involved in cell survival, apoptosis and tumorigenesis $(19,20)$.The present study revealed that intraperitoneal introduction of SRL suppressed tumour growth in the xenograft mouse model. H\&E staining of the liver sections of the SRL-treated and control-treated mice showed no difference in morphology of the liver but the expression of CD-31 was substantially lower in the SRL-treated mice. This suggests that SRL treatment also inhibits angiogenesis. After SRL intraperitoneal injection, the level of SRL in the blood was seen to be peaked at $24 \mathrm{~h}$. It is known that almost all drugs, chemicals and xenobiotics are eliminated through renal excretion; hence it was necessary to estimate the effects of SRL on kidney function $(30,31)$. There were no changes in biochemical parameters in the SRL-treated mice compared to the control-treated mice group indicating no alterations in the animal hepatic and renal functions. Biodistribution analysis showed that SRL did not accumulated in any organ apart from its temporary appearance in the kidney. Pharmacokinetic and biodistribution patterns indicate that SRL has a very fast rate of absorption and is rapidly distributed to the entire body through the circulation. SRL appears to be quickly eliminated from the body through the kidney, indicating a beneficial property of SRL as a therapeutic agent.

SRL binds to the oncofetal TF antigen and TF-related carbohydrate structures $(12,13)$. In colorectal cancer, increased expression of oncofetal TF and sialylated Tn is common (32-37) and can be detected using lectins including peanut lectin, Arachis hypogea (PNA) (38) and Sambucus nigra lectin (SNA). Many lectins have shown anticancer effects when tested in vitro and in some cases also in vivo but not many have reached clinical trials partly due to their cytotoxicity (39). Tn antigen (GalNAc-Ser/Thr)-binding Helix pomatia lectin (HPA) identifies a subset of metastatic colorectal cancer. HPA binding also reveals overexpression of sialyl-Lewis X carbohydrate antigen which is correlated with poor prognosis of colorectal cancer $(40,41)$. Viscum album var. coloratum agglutinin (VCA), binding lectin from Korean mistletoe has been used in human clinical trials at low doses for the treatment of different cancers without serious side-effects and the action seems to be beneficial (39). A mannose/sialic acid-binding plant lectin from Polygonatum cyrtonema lectin (PCL) has shown antitumour effects by inducing apoptosis and autophagy in cancer cells $(42,43)$. Two cytotoxic mistletoe isolectins designated as KML-IIU and KML-IIL were found to exhibit cytotoxicity in various human and mouse cancer cell lines (44). Mistletoe lectin has been extensively studied for its clinical use and has reached clinical trials $(45,46)$. Reports are available on the antitumor effects of Concanavalin $A$ lectin, one of the most extensively studied lectin. Clinical use of Con $\mathrm{A}$ is questionable due to its strong cytotoxic effects including the induction of hepatitis $(47,48)$.

The strong anti-proliferative, antitumour and anti-angiogenesis effects of SRL shown in vitro and in vivo in the present and previous studies with no detectable cytotoxic effects confirm the high potential of SRL as a therapeutic agent for cancer treatment.

\section{Acknowledgements}

The present study was supported by funding from the British Council under UKIERI, UGC under UPE and CPEPA and DBT-BIRAC programme.

\section{References}

1. World Health Organization: Global Health Observatory data repository 2011. Number of deaths (world) by cause. Available from: http://apps.who.int/gho/data/node.main.CODWORLD?lang=en. Last accessed 31 October 2013.

2. American Cancer Society: Cancer Facts \& Figures 2015. US Mortality Data, National Center for Health Statistic Center for Disease, Control \& Prevention, 2015. https://www.cancer.org/ research/cancer-facts-statistics/all-cancer-facts-figures/cancer-factsfigures-2015.html.

3. Ferlay J, Soerjomataram I, Dikshit R, Eser S, Mathers C, Rebelo M, Parkin MD, Forman D and Bray F: Cancer incidence and mortality worldwide: Sources, methods and major patterns in GLOBOCAN 2012. Int J Cancer 136: E359-E386, 2014.

4. Bies C, Lehr CM and Woodley JF: Lectin-mediated drug targeting: History and applications. Adv Drug Deliv Rev 56: 425-435, 2004.

5. Yu LG, Fernig DG, White MR, Spiller DG, Appleton P, Evans RC, Grierson I, Smith JA, Davies H, Gerasimenko OV, et al: Edible mushroom (Agaricus bisporus) lectin, which reversibly inhibits epithelial cell proliferation, blocks nuclear localization sequence-dependent nuclear protein import. J Biol Chem 274: 4890-4899, 1999.

6. Yu L, Fernig DG, Smith JA, Milton JD and Rhodes JM: Reversible inhibition of proliferation of epithelial cell lines by Agaricus bisporus (edible mushroom) lectin. Cancer Res 53: 4627-4632, 1993.

7. Zhao C, Sun H, Tong X and Qi Y: An antitumour lectin from the edible mushroom Agrocybe aegerita. Biochem J 374: 321-327, 2003.

8. Jiang S, Chen Y, Wang M, Yin Y, Pan Y, Gu B, Yu G, Li Y, Wong BH, Liang Y, et al: A novel lectin from Agrocybe aegerita shows high binding selectivity for terminal $\mathrm{N}$-acetylglucosamine. Biochem J 443: 369-378, 2012. 
9. Wang HX, Liu WK, Ng TB, Ooi VE and Chang ST: The immunomodulatory and antitumor activities of lectins from the mushroom Tricholoma mongolicum. Immunopharmacology 31: 205-211, 1996.

10. Li YR, Liu QH, Wang HX and Ng TB: A novel lectin with potent antitumor, mitogenic and HIV-1 reverse transcriptase inhibitory activities from the edible mushroom Pleurotus citrinopileatus. Biochim Biophys Acta 1780: 51-57, 2008.

11. Zhang GQ, Sun J, Wang HX and Ng TB: A novel lectin with antiproliferative activity from the medicinal mushroom Pholiota adiposa. Acta Biochim Pol 56: 415-421, 2009.

12. Swamy BM, Hegde GV, Naik RS and Inamdar SR: T-antigen binding lectin from the phytopathogenic fungus Sclerotium rolfsii. Lect. Biol Biochem Clin Biochem 15: 45-55, 2001.

13. Chachadi VB, Inamdar SR, Yu LG, Rhodes JM and Swamy BM: Exquisite binding specificity of Sclerotium rolfsii lectin toward TF-related O-linked mucin-type glycans. Glycoconj J 28: 49-56, 2011.

14. Yu LG: The oncofetal Thomsen-Friedenreich carbohydrate antigen in cancer progression. Glycoconj J 24: 411-420, 2007.

15. Leonidas DD, Swamy BM, Hatzopoulos GN, Gonchigar SJ, Chachadi VB, Inamdar SR, Zographos SE and Oikonomakos NG: Structural basis for the carbohydrate recognition of the Sclerotium rolfsii lectin. J Mol Biol 368: 1145-1161, 2007.

16. Inamdar SR, Savanur MA, Eligar SM, Chachadi VB, Nagre NN, Chen C, Barclays M, Ingle A, Mahajan P, Borges A, et al: The TF-antigen binding lectin from Sclerotium rolfsii inhibits growth of human colon cancer cells by inducing apoptosis in vitro and suppresses tumor growth in vivo. Glycobiology 22: 1227-1235, 2012.

17. Savanur MA, Eligar SM, Pujari R, Chen C, Mahajan P, Borges A, Shastry P, Ingle A, Kalraiya RD, Swamy BM, et al: Sclerotium rolfsii lectin induces stronger inhibition of proliferation in human breast cancer cells than normal human mammary epithelial cells by induction of cell apoptosis. PLoS One 9: e110107, 2014.

18. Eligar SM, Pujari R, Swamy BM, Shastry P and Inamdar SR: Sclerotium rolfsii lectin inhibits proliferation and induces apoptosis in human ovarian cancer cell line PA-1. Cell Prolif 45: 397-403, 2012.

19. Barkeer S, Guha N, Hothpet V, Saligrama Adavigowda D, Hegde P, Padmanaban A, Yu LG, Swamy BM and Inamdar SR: Molecular mechanism of anticancer effect of Sclerotium rolfsii lectin in HT29 cells involves differential expression of genes associated with multiple signaling pathways: A microarray analysis. Glycobiology 25: 1375-1391, 2015.

20. Barkeer S, Gudihal R, Eligar SM, Hegde P, Lu GY, Bale MS and Inamdar SR: Identification and characterization of Sclerotium rolfsii lectin (SRL) binding proteins from human colon epithelial cancer HT29 cells. Translational Biomedicine ISSN 2172-0479, 2015.

21. Sharma SK, Pedley RB, Bhatia J, Boxer GM, El-Emir E, Qureshi U, Tolner B, Lowe H, Michael NP, Minton N, et al: Sustained tumor regression of human colorectal cancer xenografts using a multifunctional mannosylated fusion protein in antibody-directed enzyme prodrug therapy. Clin Cancer Res 11: 814-825, 2005

22. Vallespí MG, Pimentel G, Cabrales-Rico A, Garza J, Oliva B, Mendoza O, Gomez Y, Basaco T, Sánchez I, Calderón C, et al: Antitumor efficacy, pharmacokinetic and biodistribution studies of the anticancer peptide CIGB-552 in mouse models. J Pept Sci 20: $850-859,2014$

23. Ingle $\mathrm{AD}$ and Hosetti $\mathrm{BB}$ : Use of immuno-compromised mouse model for establishment and study of human animal tumours. Indian J Vet Pathol 34: 156-161, 2010.

24. Simpson RJ: Homogenization of mammalian tissue. Cold Spring Harb Protoc pdb prot 5455, 2010. https://doi.org/10.1101/pdb. prot5455. https://doi.org/10.1101/pdb.prot5455.

25. Burden DW: Guide to the Homogenization of Biological Samples. Random Primers. Vol. 7, 2008, pp1-14, 2008. http://www.opsdiagnostics.com/notes/ranpri/Homogenization\%20Guide\%20ver. .pdf.

26. Hartmann C, Smeyers-Verbeke J, Massart DL and McDowall RD: Validation of bioanalytical chromatographic methods. J Pharm Biomed Anal 17: 193-218, 1998.

27. Ahn JE, Karlsson MO, Dunne A and Ludden TM: Likelihood based approaches to handling data below the quantification limit using NONMEM VI. J Pharmacokinet Pharmacodyn 35: 401-421, 2008.
28. Jusko WJ: Use of pharmacokinetic data below lower limit of quantitation values. Pharm Res 29: 2628-2631, 2012.

29. Beal SL: Ways to fit a PK model with some data below the quantification limit. J Pharmacokinet Pharmacodyn 28: 481-504, 2001.

30. Sallam H, El-Serafi I, Meijer L and Hassan M: Pharmacokinetics and biodistribution of the cyclin-dependent kinase inhibitor -CR8- in mice. BMC Pharmacol Toxicol 14: 50, 2013.

31. Khlebtsov N and Dykman L: Biodistribution and toxicity of engineered gold nanoparticles: A review of in vitro and in vivo studies. Chem Soc Rev 40: 1647-1671, 2011.

32. Ghazarian H, Idoni B and Oppenheimer SB: A glycobiology review: Carbohydrates, lectins and implications in cancer therapeutics. Acta Histochem 113: 236-247, 2011.

33. Campbell BJ, Finnie IA, Hounsell EF and Rhodes JM: Direct demonstration of increased expression of Thomsen-Friedenreich (TF) antigen in colonic adenocarcinoma and ulcerative colitis mucin and its concealment in normal mucin. J Clin Invest 95: 571-576, 1995.

34. Singh R, Campbell BJ, Yu LG, Fernig DG, Milton JD, Goodlad RA, FitzGerald AJ and Rhodes JM: Cell surfaceexpressed Thomsen-Friedenreich antigen in colon cancer is predominantly carried on high molecular weight splice variants of CD44. Glycobiology 11: 587-592, 2001.

35. Hanisch FG and Baldus SE: The Thomsen-Friedenreich (TF) antigen: A critical review on the structural, biosynthetic and histochemical aspects of a pancarcinoma-associated antigen. Histol Histopathol 12: 263-281, 1997.

36. Almogren A, Abdullah J, Ghapure K, Ferguson K, Glinsky VV and Rittenhouse-Olson K: Anti-Thomsen-Friedenreich-Ag (antiTF-Ag) potential for cancer therapy. Front Biosci (Schol Ed) 4: 840-863, 2012.

37. Belov L, Zhou J and Christopherson RI: Cell surface markers in colorectal cancer prognosis. Int J Mol Sci 12: 78-113, 2010.

38. Singh R, Subramanian S, Rhodes JM and Campbell BJ: Peanut lectin stimulates proliferation of colon cancer cells by interaction with glycosylated CD44v6 isoforms and consequential activation of c-Met and MAPK: Functional implications for disease-associated glycosylation changes. Glycobiology 16: 594-601, 2006.

39. Yau T, Dan X, Ng CC and Ng TB: Lectins with potential for anti-cancer therapy. Molecules 20: 3791-3810, 2015.

40. Mitchell BS and Schumacher U: The use of the lectin Helix pomatia agglutinin (HPA) as a prognostic indicator and as a tool in cancer research. Histol Histopathol 14: 217-226, 1999.

41. Peiris D, Ossondo M, Fry S, Loizidou M, Smith-Ravin J and Dwek MV: Identification of $O$-linked glycoproteins binding to the lectin Helix pomatia agglutinin as markers of metastatic colorectal cancer. PLoS One 10: e0138345, 2015.

42. Liu B, Wu JM, Li J, Liu JJ, Li WW, Li CY, Xu HL and Bao JK: Polygonatum cyrtonema lectin induces murine fibrosarcoma L929 cell apoptosis and autophagy via blocking Ras-Raf and PI3K-Akt signaling pathways. Biochimie 92: 1934-1938, 2010.

43. Wang SY, Yu QJ, Bao JK and Liu B: Polygonatum cyrtonema lectin, a potential antineoplastic drug targeting programmed cell death pathways. Biochem Biophys Res Commun 406: 497-500, 2011.

44. Kang TB, Song SK, Yoon TJ, Yoo YC, Lee KH, Her E and Kim JB: Isolation and characterization of two Korean mistletoe lectins. J Biochem Mol Biol 40: 959-965, 2007.

45. Yoon TJ, Yoo YC, Kang TB, Song SK, Lee KB, Her E, Song KS and Kim JB: Antitumor activity of the Korean mistletoe lectin is attributed to activation of macrophages and NK cells. Arch Pharm Res 26: 861-867, 2003.

46. Rostock M, Huber R, Greiner T, Fritz P, Scheer R, Schueler J and Fiebig HH: Anticancer activity of a lectin-rich mistletoe extract injected intratumorally into human pancreatic cancer xenografts. Anticancer Res 25: 1969-1975, 2005.

47. Miyagi T, Takehara T, Tatsumi T, Suzuki T, Jinushi M, Kanazawa Y, Hiramatsu N, Kanto T, Tsuji S, Hori M, et al: Concanavalin a injection activates intrahepatic innate immune cells to provoke an antitumor effect in murine liver. Hepatology 40: 1190-1196, 2004.

48. Lei HY and Chang CP: Lectin of Concanavalin A as an antihepatoma therapeutic agent. J Biomed Sci 16: 10, 2009. 